RAEIC, Revista de la Asociación Española de Investigación

\title{
La peligrosa tentación de la censura frente a las fake news. Una aproximación a los desafíos que suponen las noticias falsas para el periodismo
}

The dangerous temptation of censorship against fake news. Towards the challenge of fake news for journalism.

Costa, José María

Universidad Nacional de Asunción (UNA)

pepecosta2007@gmail.com

Forma de citar este artículo:

Costa, J. M. (2020). "La peligrosa tentación de la censura frente a las fake news. Una aproximación a los desafíos que suponen las noticias falsas para el periodismo", RAEIC, Revista de la Asociación Española de Investigación de la Comunicación, vol. 7, núm. 14, 150-171. https://doi.org/10.24137/raeic.7.14.7

\section{Resumen:}

Las fake news constituyen hoy día uno de los más graves problemas en materia de información y comunicación. El impacto de las noticias falsas, así como su incremento exponencial a partir de la expansión de las redes sociales de internet, concitan la preocupación de diversos sectores. En el presente artículo, se aborda una mirada global del problema enfocado especialmente en su relación con el periodismo. A este efecto, se exponen datos preliminares de un estudio exploratorio sobre actitudes y opiniones 
de los periodistas sobre las fake news, así como la notable tendencia a preferir estrategias que incluyan restricciones y censura como forma de "combate" a la diseminación de noticias falsas.

Palabras clave: periodismo, fake news, censura, información, desinformación.

\section{Abstract:}

Fake news is one of the most serious information and communication problems today. The impact of fake news, as well as its exponential increase from the expansion of social networks on the internet, raise the concern of various sectors. In this article, a global view of the problem is addressed, especially focused on its relationship with journalism. To this effect, preliminary data from an exploratory study on journalists' attitudes and opinions on fake news are exposed, as well as the notable tendency to prefer strategies that include restrictions and censorship as a form of "combat" to the dissemination of false news.

Palabras clave: journalism, fake news, censorship, information, disinformation.

\section{INTRODUCCIÓN}

Las fake news son caracterizadas como un gran problema en la comunicación actual. Un problema que debe ser combatido para neutralizar o evitar las consecuencias de desinformación y manipulación política, entre otras, que trae para la sociedad contemporánea. El debate sobre las fake news avanza en varios sentidos, pero fundamentalmente en torno a cómo combatirlas. ¿Qué estrategia es admisible y adecuada en el marco de la libertad de expresión para luchar contra las fake news?

Esta es una de las líneas de exploración desarrolladas en un análisis que vincula al periodismo y los periodistas con este fenómeno de la comunicación masiva que se ve potenciado por la expansión actual de internet y los medios tecnológicos. En la Universidad Nacional de Asunción, a partir de las cátedras de Derecho de la Información y de Teoría y Práctica de Periodismo II, se propició un estudio que incluyó una encuesta 
de opinión sobre las fake news aplicada a periodistas y comunicadores sociales, estudio del cual se exponen algunos avances en este artículo, enfocados en esta intención de aportar al debate de qué tipo de respuestas deben tener la sociedad y los actores de la comunicación social con relación a la problemática de la proliferación de noticias falsas.

\section{LAS “FAKE NEWS” MIRADAS DESDE DISTINTAS PERSPECTIVAS}

Internet y sus redes sociales han traído a la humanidad un tiempo de incesante y abrumadora circulación de datos e información. La "sociedad de la información" caracterizada por académicos y observadores de los '90, en los tiempos germinales de la "red de redes", ha sido ampliamente superada en sus expectativas y alcances, en su amplitud y potencialidades en menos de dos décadas del continuo proceso de expansión de internet.

La "sociedad red" (Castells, 2020) ha traído grandes y nuevos desafíos para la humanidad. Su desarrollo no solo ofrece nuevas oportunidades, sino también nuevos (o rediseñados) conflictos de poder, así como, renovados modelos para las pretensiones hegemónicas políticas e ideológicas. Más que un ámbito de libertades, sencillamente, las redes sociales de internet se han convertido en el "espacio de lucha por la libertad" como dice Castells, y han sido penetrados por los poderes fácticos "con desinformación, con manipulación" (Castells, 2020).

Con el impacto de internet en las comunicaciones, y sobre todo en la rapidez de generación y distribución de las informaciones, sobrevinieron nuevas problemáticas, muchas de las cuales, si bien existieron antaño, en este nuevo contexto se vieron exponencialmente multiplicados.

Una de dichas problemáticas es la de las "fake news" o noticias falsas, o como otros denominan, "bulos". Fenómeno contemporáneo, pero de presencia milenaria, pues desde que existe la palabra como expresión del pensamiento, y desde que los seres humanos se han relacionado entre sí, también existe la mentira en la comunicación. El relato bíblico del libro del Génesis, en el texto sagrado de la cristiandad, con la historia 
de Adán, Eva y la Serpiente, es una ilustrativa metáfora de esa existencia originaria del engaño y la mentira en la relación entre los seres humanos.

Hoy día, hablar de mentiras o falsedades en la comunicación nos remite de forma automática a esta nueva denominación plasmada en el término de "fake news". Información falsa, mentira disfrazada de información, desinformación presentada como información real... Es la realidad que hoy día preocupa a diferentes ámbitos de la sociedad por las consecuencias que su diseminación puede tener en las vidas de las personas, en el manejo de una sociedad, en los procesos políticos y electorales, en la manipulación de la opinión pública, etc.

Para la Red del Periodismo Ético (EJN, por sus siglas en inglés), las "fake news" son "toda aquella información generada y publicada deliberadamente para engañar e inducir a terceros a creer falsedades o poner en duda hechos verificables" (Ethical Journalism Network, 2017). En este concepto, queda claro que la intencionalidad del engaño es componente esencial de las fake news.

Con mayor especificidad en la descripción, el Manual de Educación y Capacitación en Periodismo de la UNESCO, con el título de "Periodismo, noticias falsas y desinformación" (UNESCO, 2020), establece tres categorías:

- Desinformación: información que es falsa y deliberadamente creada para dañar a una persona, grupo social, organización o país.

- Mal-información: información que se basa en la realidad, utilizada para infligir daños a una persona, grupo social, organización o país.

- Información errónea: información falsa pero no tratada con la intención de causar daño.

La Federación Internacional de Periodistas sostiene que las noticias falsas provocan en la sociedad "un peligroso círculo de desinformación" con gravitantes consecuencias en terrenos como el político y el económico, todo lo cual sucede en un contexto de "posverdad" en el que los hechos objetivos son menos importantes que las emociones y las creencias a la hora de modelar la opinión pública (IFJ, 2019). 


\section{PERIODISMO, MANIPULACIÓN Y “FAKE NEWS"}

Para el periodismo, la existencia de noticias falsas no es una novedad (como tampoco lo es para la sociedad en general, como se dijo en las páginas preliminares). Si bien en el sustrato deontológico de esta profesión el acto de informar se sostiene sobre la verdad y el más fiel y veraz relato del hecho, el periodismo no ha estado exento de sucesos donde la falsedad y la mentira han generado situaciones de crisis para su capital esencial, que es la credibilidad del público.

Como cualquier actividad humana, el periodismo es pasible de tener y generar errores. Pero lo que no es ética ni legalmente admisible es la mentira o la calumnia, esto es, la divulgación pública de un hecho a sabiendas de su falsedad.

Un fallo judicial ampliamente conocido -el que resolviera en 1964 el caso del New York Times vs. Sullivan- y dictado por la Corte Suprema de Justicia federal de los Estados Unidos de América, es el principal orientador de esta necesaria diferencia entre el error no buscado y la mentira "con conocimiento de causa" que pueden aparecer en la actividad periodística y pueden generar diferentes resultados y responsabilidades en términos ético-legales.

En aquel caso judicial, el periódico neoyorkino fue objeto de una demanda civil por parte de un funcionario público, L.B. Sullivan, comisionado de la ciudad de Montgomery, Alabama, quien reclamaba ser indemnizado por la publicación de una solicitada en el NYT. Según Sullivan, dicha nota contenía datos inexactos e información falsa sobre la actuación de fuerzas policiales (que estaban a su cargo) en incidentes con estudiantes y activistas que protestaban contra las políticas segregacionistas en el estado de Alabama. Los jueces de la Corte Federal sentenciaron que el periódico no podía ser condenado y el funcionario indemnizado, salvo que éste probara que la publicación fue hecha con "real malicia", es decir, con total conocimiento de que era falsa la información o el periódico haya actuado con temeridad y despreocupación acerca de si era veraz o no dicha información. Ya reflexionaban entonces los jueces del alto tribunal que admitir una sanción (civil, resarcitoria, como era en ese caso) a un periódico por haber publicado una información cuya falsedad fuera comprobada después, no era compatible con los 
estándares de la libertad de expresión, pues con dicho antecedente la prensa se vería limitada y hasta autocensurada en sus publicaciones por temor a demandas civiles.

Si bien esta "doctrina de la real malicia" asentada por la Corte norteamericana fue un fuerte respaldo a la tarea periodística y sus alcances se fueron ampliando a lo largo de décadas, así como su fuerza y gravitación se consolidó en los ámbitos tribunalicios, esto no ha evitado que en la historia reciente del periodismo sigan apareciendo varios casos notorios de noticias falsas difundidas por la prensa tradicional incluso. Ni que la comunicación mediática sea asimismo utilizada en operaciones de propaganda política y en complots sustentados sobre la desinformación puntualmente dirigida a objetivos concretos. Mencionaremos casos al respecto.

En 1981, el Washington Post debió admitir públicamente que una periodista de su redacción, Janet Cooke, había prácticamente inventado un reportaje sobre un niño drogadicto, nota cuya relevancia e impacto social le valieron ganar el Premio Pulitzer, al que luego debió renunciar.

En su edición dominical del 11 de mayo de 2003, el periódico The New York Times publicó una investigación propia sobre los artículos engañosos y con historias falsas que había publicado, semanas antes en sus páginas, un periodista de su propio staff: Jayson Blair.

No fueron, no han sido ni serán, probablemente, casos únicos. Pero la prensa que se precia de que su principal capital es la credibilidad, aún expuesta a errores o a actitudes antiéticas y maliciosas de sus propios reporteros, siempre se vio obligada a admitir o desmentir sus propias publicaciones. Y en muchos casos, como precaución, han aplicado o aplican estándares de "fact checking" internos, incluso. Esto, en realidad, es el antecedente de las extendidas prácticas de "fact checking" a cargo de organizaciones internacionales, de la sociedad civil o agrupaciones de periodistas profesionales que, inicialmente en Europa y luego extendidas por todo el orbe, vienen actuando con la bandera de la lucha contra las "fake news" utilizando la metodología de chequear y desmentir las desinformaciones propaladas por diversos medios, especialmente en las redes de internet. 
Los medios de comunicación tampoco han estado exentos de ser parte o caer en las garras de la manipulación propagandística. La periodista española Marta Peirano nos recuerda en su más reciente libro (Peirano, 2019) aquella llamada “Operación Infektion", en los años 80, cuyo punto de partida fue una casi insignificante carta al editor en un periódico de Delhi, el Patriot, en la que un "conocido científico" aseguraba que el virus del VIH sida había sido creado por orden del Pentágono en un laboratorio ubicado en Maryland, EEUU, para acabar con la población afroamericana y gay. ¿ No nos trae reminiscencias actuales este caso con los rumores que hoy día recorren las redes sobre el "origen" del Coronavirus?

Pues bien, aquella había sido una estrategia de desinformación que -luego se revelófue ideada por la KGB soviética desde su Departamento de Dezinformatsiya, de acuerdo a las confesiones de exagentes que incluso dieron el dato de que el periódico Patriot (el que difundió originalmente la especie) había sido creado por la propia organización de espionaje ruso en 1962 en plena guerra fría. En marzo de 1987, aquella casi marginal nota en un periódico del tercer mundo adquiría nivel global a través de la Cadena CBS, la tercera más grande del mundo. $Y$ todo era apenas parte de una campaña sucia de desinformación con fines políticos concretos.

Si se buscara otro ejemplo relevante de manipulación propagandística con amplio sostén en el espectro mediático, bastaría evocar la guerra lanzada por George W. Bush contra Irak en el 2003, basada en la supuesta existencia de instalaciones para la producción de armas de destrucción masiva bajo el gobierno de Saddam Hussein. El desmentido y la aceptación de tamaña desinformación milimétricamente planificada llegaron después de una guerra que costó más de 200 mil vidas.

Peirano sostiene que la principal diferencia entre la propaganda y la desinformación es que la primera "usa los medios de comunicación de maneras éticamente dudosas para convencer de un mensaje, mientras que la segunda se inventa el propio mensaje, que está diseñado para engañar, asustar, confundir y manipular a su objetivo". La autora señala que la campaña de desinformación empieza por "identificar las grietas preexistentes para alimentarlas y llevarlas al extremo" (Peirano, 2019) 
La desinformación es ese submundo que ocurre por debajo de la información y que cada vez con más frecuencia y obscenidad aflora en lo cotidiano con la viralización de mensajes con apariencia de verdad que responden generalmente a estrategias bien articuladas de manipulación. En este contexto, con la proliferación y velocidad extrema de difusión de las "fake news", a caballo de las nuevas tecnologías y las redes sociales de internet, el periodismo también siente el impacto.

De acuerdo a Ivor Gaber, profesor de periodismo de la Universidad de Sussex, en Reino Unido, la desinformación ha existido siempre "a partir del momento en que se cobró conciencia de la influencia de los medios en la opinión pública" (UNESCO, 2017). En cambio, dice, "sí que es nuevo y realmente preocupante el hecho de que la desinformación se propague con una celeridad y amplitud inauditas por plataformas digitales como Google o Facebook". Para él, "las informaciones falsas han transformado el periodismo, ya que le plantean un serio desafío en la medida en que no siempre resulta evidente distinguir lo que hay en ellas de verdadero y falso. No obstante, los bulos e informaciones trucadas contribuyen al mismo tiempo a reforzar considerablemente el papel del periodismo. Si hay alguien capaz de denunciar la información falsa, son precisamente los periodistas, los periodistas responsables evidentemente" (UNESCO, 2017).

Al respecto de estos temas, palabras esclarecedoras ofrecía también en vida Javier Darío Restrepo, el maestro colombiano del periodismo, desde su "Consultorio Ético" en la Fundación del Nuevo Periodismo Iberoamericano (hoy Fundación Gabo, en homenaje a su creador, el gran escritor Gabriel García Márquez). Sostenía Restrepo que "tanto como la libertad, la verdad es esencial para el ejercicio periodístico y para la vida de la sociedad, y es el servicio que el periodista le debe a la sociedad" (Restrepo, 2019).

"Las noticias falsas o trucadas no son periodismo. Tendríamos que preguntarnos qué le hemos hecho los medios informativos tradicionales al periodismo para que esas noticias falsas se acepten y difundan con tanta facilidad", se plantea, por su parte, Catarina Carvalho, jefa de redacción de The Global Media Group, de Portugal, según se consigna en una serie de entrevistas publicadas por UNESCO sobre el tema (UNESCO, 2017). La 
comunicadora señala que para impedir que las informaciones falsas "tengan tanto poder e influencia", los periodistas "deberíamos hacer un examen de conciencia y preguntarnos si estamos haciendo lo que debemos, si nuestras conductas son acertadas y si practicamos un periodismo ético".

\section{PERIODISMO Y PANDEMIA}

La expansión y el impacto de las fake news en estos tiempos de pandemia vividos a nivel global han sido destacados por numerosos expertos, en múltiples paneles y seminarios, en informes, en notas periodísticas y en las propias redes sociales que son identificadas como las autopistas de mayor circulación de esta "desinfodemia" paralela a la pandemia del COVID-19.

Con motivo del Día Mundial de la Libertad de Prensa, este año 2020, UNESCO publicó un conjunto de documentos, recursos e informes bajo el título de "Periodismo, libertad de prensa y COVID-19", en el que se analizan todas las formas y mecanismos con que la desinformación se propaga a través de los medios y plataformas de comunicación. Según la organización, un tercio de los usuarios de las redes sociales son conscientes de haber visto información falsa o engañosa sobre la pandemia, mientras que el $42 \%$ de los tweets relacionados con COVID-19 provenían regularmente de bots en el período de análisis (marzo/abril 2020). A la par de esto, en el curso de "Periodismo en tiempos de pandemia", promovido durante mayo de este año por UNESCO y el Knight Center for Journalism de la Universidad de Texas, la tutora Maryn Mackenna, periodista científica, mencionaba que en el mes de marzo, 40 millones de publicaciones relacionadas con COVID fueron identificadas por Facebook como problemáticas y necesitadas de una advertencia (Mackenna, 2020).

En un webinario realizado en mayo de 2020, Silvio Waisbord expresó que la pandemia "es un terremoto que sacude a la vez a sistemas políticos, económicos, sociales e informativos", agravado en este último aspecto por la precariedad con la que se manejan los periodistas y el desconocimiento generalizado sobre las características del virus, todo lo cual hace que los periodistas "no encuentren guías claras para la cobertura" y tengan acceso dificultado a fuentes y sitios confiables. Frente a esto, el 
catedrático de la Escuela de Medios de la George Washington University, apunta que se vuelve a validar y certificar "la regla básica del buen periodismo: chequear la información", la cual, según él, debe regir para cualquier persona que tenga el rol de comunicar, incluso en las redes sociales de internet (Waisbord, 2020).

La actividad de "fact checking", por cierto, en estos tiempos de pandemia ha crecido bastante y los sitios y organizaciones que encaran este servicio se han visto hasta desbordados. Cerca de un centenar de estas entidades se nuclearon desde enero del 2020 alrededor de un trabajo colaborativo para chequear información específica en torno a la pandemia de COVID-19. Bajo el título de \#DatosCoronavirus, este servicio es una estrategia para contrarrestar el flujo e impacto de las noticias falsas (ver https://www.poynter.org/ifcn-covid-19-misinformation/ )

Las redes de chequeo de datos, sin dudas, constituyen un valioso aporte en este combate a la desinformación, pero nunca resultarán suficientes quizás para tantas oleadas de noticias y datos falsos o manipulados que pululan en las redes de internet.

\section{LOS PERIODISTAS Y LAS “FAKE NEWS" EN TIEMPOS DE PANDEMIA. UN ESTUDIO EXPLORATORIO}

Tal como se señaló en la introducción, dicho todo lo anterior, resulta pertinente exponer y compartir los avances de un estudio exploratorio sobre "Los periodistas y las fake news" desarrollado desde las cátedras de Derecho de la Información y de Teoría y Práctica de Periodismo de la Universidad Nacional de Asunción. En el marco de dicho trabajo, se propuso sondear sobre las percepciones y actitudes de profesionales del periodismo y la comunicación social frente al fenómeno de la desinformación en el tiempo de la pandemia por el virus del Covid-19, en un marco amplio que incluyó indagar sobre las alternativas que se ven para combatir a las fake news en este contexto.

El instrumento utilizado para indagar las opiniones y actitudes de los periodistas fue un cuestionario de 15 preguntas, distribuido en dos niveles: un nivel nacional (con periodistas que ejercen su profesión en Paraguay) y un nivel internacional (centrado en comunicadores que ejercen su profesión en países de la región latinoamericana). 
Se escogió un sistema de muestreo de carácter no probabilístico y por conveniencia (o intencional), con cuestionarios enviados en forma individual vía mail y/o a través de la aplicación de mensajes Whatsapp, con contactos incluidos en una base de datos desarrollada en el marco de las actividades de las Cátedras participantes. De 120 cuestionarios enviados a otros tantos periodistas en el ámbito nacional, se recibieron 72 respuestas; mientras que en el nivel latinoamericano, de 55 formularios distribuidos, se han recolectado 37 respuestas válidas. Las encuestas fueron distribuidas y recibidas entre los días 1 y 12 de junio del 2020.

\subsection{GRAN PROPAGACIÓN DE "FAKE NEWS" SOBRE EL CORONAVIRUS DURANTE EL TIEMPO DE PANDEMIA}

La alta propagación de noticias de contenido falso sobre el coronavirus durante la pandemia del Covid-19 es una de las constataciones emergentes del sondeo.

En el ámbito nacional paraguayo, el $70,8 \%$ de los encuestados dijo haber leído o escuchado "muchas veces" noticias falsas sobre el tema durante el período de pandemia (marzo a junio/2020), mientras que un 23,6\% mencionó haberlas leído/escuchado varias veces (entre 2 y 4 veces). Las cifras en el ámbito latinoamericano son similares ( $70 \%$ y $30 \%$, con esas opciones, respectivamente). (Ver Gráficos 1 y 2)

Gráfico 1. Grupo Paraguay.

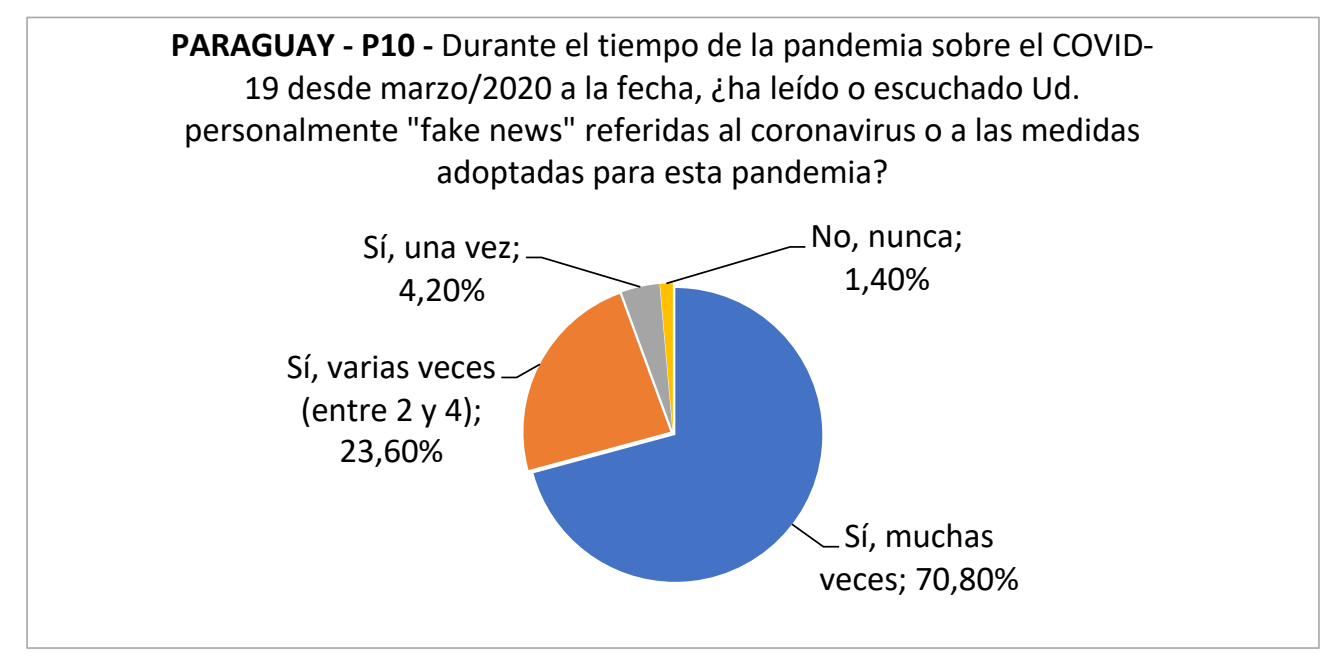


Gráfico 2. Grupo América Latina.

AM LAT - P10 - Durante el tiempo de la pandemia sobre el COVID-19 desde marzo/2020 a la fecha, ¿̇ha leído o escuchado Ud. personalmente "fake news" referidas al coronavirus o a las medidas adoptadas para esta pandemia?

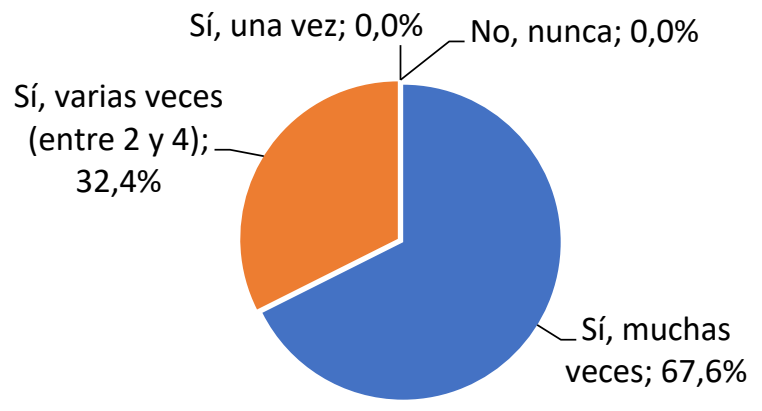

Más de dos tercios de los encuestados que ejercen el periodismo en Paraguay $(68,1 \%)$ coincidió en que durante la temporada de pandemia hubo "muchísima circulación" de noticias falsas, y un $26,4 \%$ dijo que tuvo una "mediana circulación". Entre quienes ejercen el periodismo en otros países de la región, un 70,3\% consideró que hubo "muchísima circulación" de "fake news", mientras que un $24,3 \%$ cree que ha habido una "mediana circulación".

En otra pregunta, en la cual al encuestado se le pedía señalar en qué tipo de medios había visto/leído/escuchado "fake news", y pudiendo marcar varias opciones a la vez, la mayor prevalencia ha sido la de las redes sociales o aplicativos de comunicación frente a los medios tradicionales, tanto en el ámbito nacional (WhatsApp 83,3\%, Facebook $76,4 \%$ y Twitter $54,2 \%$ ) como en el internacional (WhatsApp 96,7\%, Facebook $86,7 \%$ y Twitter 83,3\%).

\subsection{LA TENDENCIA A PREFERIR LA CENSURA Y LA SANCIÓN COMO “SOLUCIONES"}

Otra de las principales constataciones resultantes a partir de estos avances del estudio es que, en cuanto a la opinión de los propios periodistas, estamos probablemente ante una tendencia muy notable hacia considerar que el bloqueo y la censura en redes sociales son alternativas deseables para el "combate" a las "fake news". 
Dos tercios de los consultados $(68,1 \%)$ en el capítulo paraguayo han considerado que las corporaciones que administran redes sociales de internet, como Twitter o Facebook, deben tener la "facultad" de bloquear o cerrar las cuentas que publican fake news. Solamente un $12,5 \%$ consideró que no debían poseer dicha atribución, y un 19,4\% dijo "no tener opinión sobre el tema".

Gráfico 3. Grupo Paraguay.

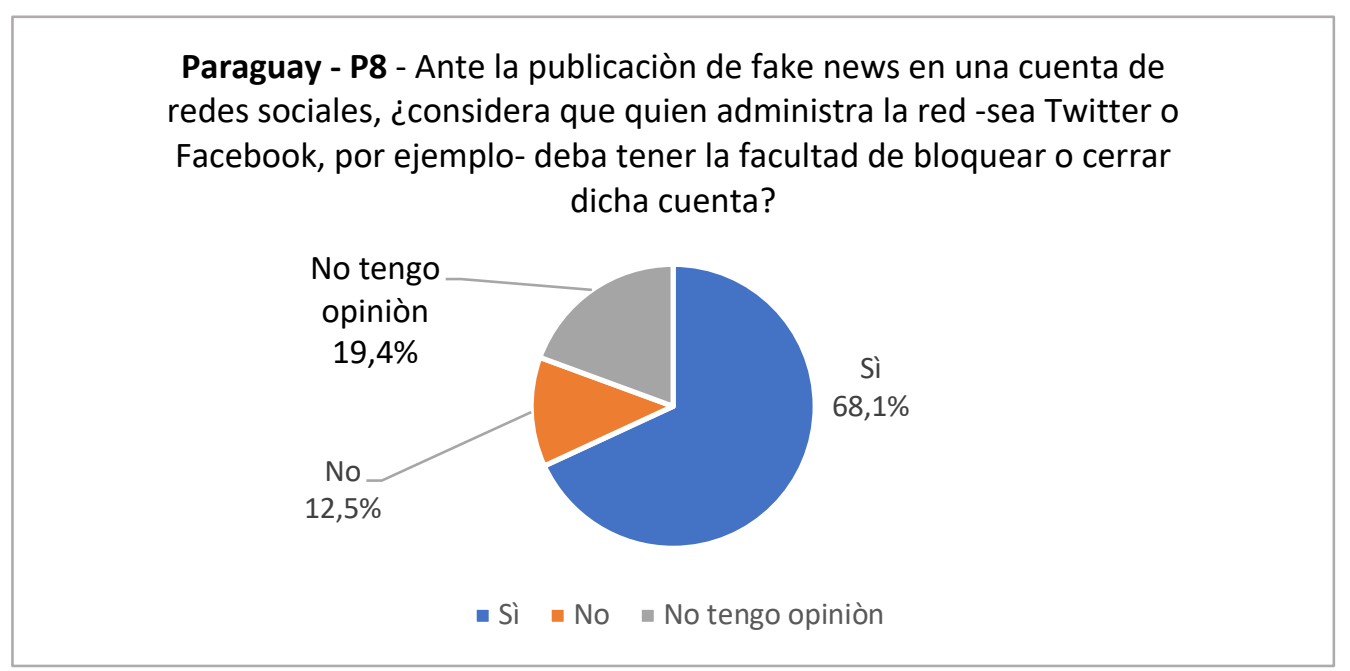

En el ámbito internacional, las tendencias son muy similares: un $67,6 \%$ de los encuestados dijo que Twitter y Facebook deben contar con dicha facultad de "bloqueo o cierre" de cuentas, mientras que un $18,9 \%$ consideró que no debían tener dicha potestad. El 13,5\% de los preguntados dijo no tener opinión sobre el asunto.

Gráfico 4. Grupo Paraguay.

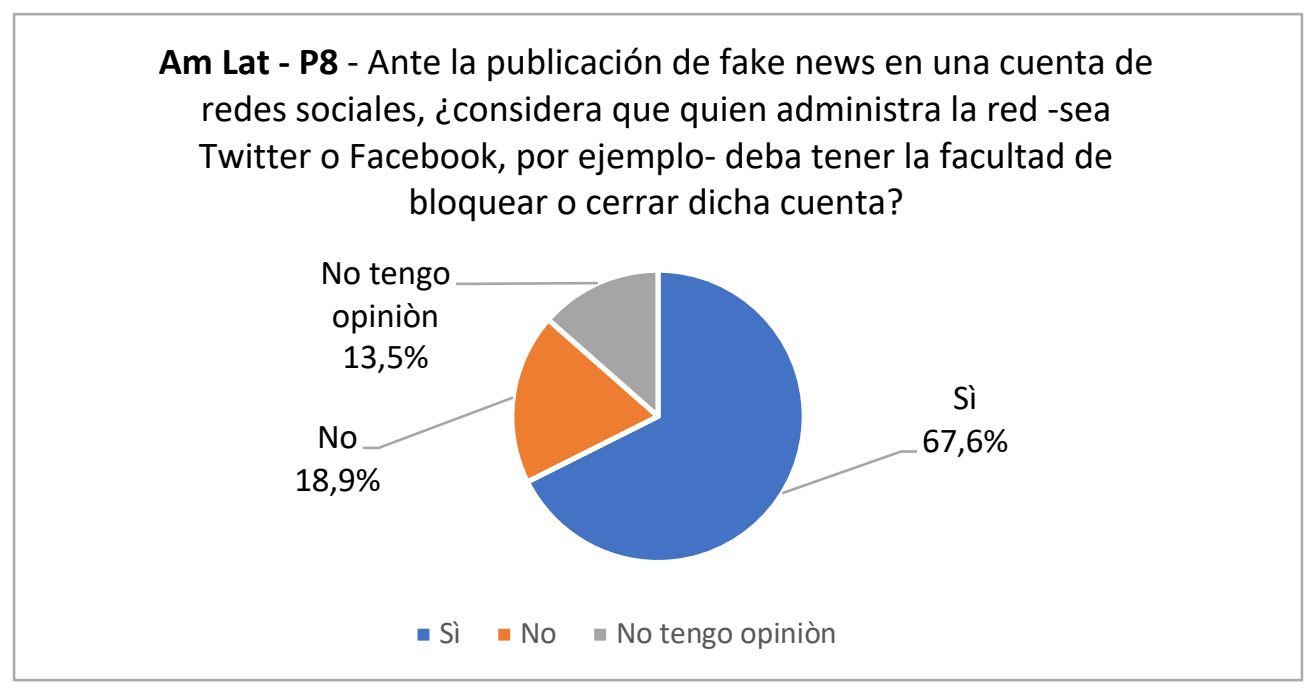

RAEIC, Revista de la Asociación Española de Investigación de la Comunicación vol. 7, núm. 14 (2020), 150-171 
Estas tendencias a preferir en cierto modo la censura como herramienta de combate contra las fake news se reafirma en otras preguntas del mismo estudio.

En una de ellas se consultó a los encuestados cuáles consideraría como "mejores estrategias" para combatir la proliferación de las fake news.

El conjunto de "estrategias" puestas a consideración estaba constituido por tres de tipo "sancionatorio" (bloqueos, sanciones penales, cierre de cuentas en redes sociales) y tres de tipo "proactivo o constructivo" (mayor información y contexto, mecanismos de concientización y educación, recursos de "fact checking"). Estas fueron, específicamente, las "estrategias" expuestas a los encuestados, quienes podían marcar varias opciones libremente.

- Reportar y pedir bloqueo de cuentas en redes sociales que publican fake news

- Establecer sanciones legales para quienes divulguen fake news en redes sociales

- Que las redes como Twitter y Facebook, retiren las cuentas que difunden fake news

- Ofrecer mayor información y contexto referido a los temas abordados por las fake news

- Promover mecanismos de concientización y educación sobre las fake news

- Contar con páginas que hagan "chequeo de noticias" para advertir sobre las fake news

Para los periodistas encuestados en el capítulo nacional, las opciones que implican sanciones y/o censura parecen ser las preferidas. Así, la opción con mayor preferencia por sobre las restantes fue la del establecimiento y aplicación de sanciones legales para quienes las difundan o compartan (obtuvo un $51,4 \%$ de preferencia), mientras un $40,3 \%$ de preferencia fue para la opción de "reportar y pedir el bloqueo de cuentas" que difundan o repliquen dichas informaciones falsas. El 33,1\% se llevó la opción que admite que las corporaciones que manejan dichas redes, como Twitter y Facebook, retiren las cuentas que difunden fake news.

En orden a las opciones de medidas más proactivas y con sentido constructivo, el $43 \%$ de preferencia fue para la estrategia de promover la concientización de ciudadanos en 
torno a este tema, en tanto el $41,7 \%$ de preferencia fue para la estrategia de implementación de páginas web que hagan el "fact checking" sobre noticias difundidas en las redes. Hubo un $31,9 \%$ de preferencia para la opción de "ofrecer mayor información y contexto de las noticias".

Llevada la misma consulta al contexto internacional, hay una mayor y notoria preferencia por una respuesta más "constructiva" que sancionatoria. La opción más votada, con un $78,4 \%$, fue la de "promover mecanismos de concientización y educación sobre las fake news". Sin embargo, pese a esta mayor preferencia inicial de una estrategia "proactiva", en el rango inmediato inferior, igualaron en porcentaje de preferencia $(54,1 \%)$ tres estrategias de tipo "sancionatorio" (Reportar y pedir bloqueo de cuentas en redes sociales; establecer sanciones legales para quienes divulguen fake news; y que las redes como Twitter y Facebook, retiren las cuentas que difunden fake news).

\subsection{LOS PERIODISTAS, LA INFORMACIÓN Y LAS NOTICIAS FALSAS}

Como parte del estudio, también se ha pretendido indagar las acciones y actitudes de los periodistas y comunicadores con respecto al manejo de la información, así como en relación a su experiencia pasada en cuanto a la divulgación de informaciones erróneas o no confirmadas.

Al respecto, se les consultó si en su tarea periodística o en sus redes sociales personales habían publicado o compartido alguna vez información que luego resultó ser falsa. En cuanto al capítulo nacional paraguayo, en las respuestas referidas a lo sucedido en el ámbito de la tarea periodística aparecen valores que señalan una mayor "precaución", por cuanto, por ejemplo, mientras un 63,9\% dijo que "nunca" ha publicado una noticia que resultó ser falsa en su actividad periodística, sin embargo, en sus redes sociales personales, ese porcentaje se reduce al $45,8 \%$. Un $13,9 \%$ dijo haber publicado una noticia falsa en su tarea periodística "una vez", mientras que en el marco de las redes sociales personales ese valor sube al $27,8 \%$. Finalmente, un $20,8 \%$ dijo haber publicado noticias que resultaron falsas en su tarea periodística "más de una vez", mientras que en el contexto de las redes sociales personales ese porcentaje es de $26,4 \%$. 
Los números en el nivel internacional aparecen con mejor performance. Un 67,6\% de consultados dijo que "nunca", en su actividad periodística, publicó algo que resultó luego falso, mientras que el porcentaje se mantiene similar $(64,9 \%)$ en cuanto a ese tipo de difusión en las redes sociales personales. Sin embargo, el porcentaje de quienes dijeron haber publicado una noticia falsa "una vez" en la tarea profesional (21,6\%) resulta mayor que el reflejado por los periodistas paraguayos, en tanto que, con relación a la difusión en redes sociales personales el porcentaje $(16,2 \%)$ es menor que el declarado por los connacionales.

Estos indicadores parecen sugerir un cierto relajamiento de la responsabilidad y la tarea de verificación a la hora de actuar en forma personal, en redes sociales, en comparación con el cuidado o la actividad de verificación que estaría más regular y eficazmente llevada en la tarea profesional periodística. La interrogante que queda flotando es cómo este tipo de "relajamiento" de la actitud frente a la divulgación de información estaría afectando o podría afectar la base misma de la credibilidad del periodista, en lo personal, o la de su medio, por extensión. Y además, cómo se compatibiliza esto con la relevancia e influencia que el periodista tiene por efecto de su propia profesión frente a la sociedad, las cuales sin duda se proyectan incluso en su presencia personalizada en redes sociales de internet.

\section{DE LA TENTACIÓN DE LA CENSURA A LA NECESIDAD DE UN PERIODISMO DE CALIDAD}

Hasta aquí, el recorrido de las reflexiones volcadas a mirar y analizar la realidad cada vez más impactante de las fake news en el mundo actual de la comunicación y la información lleva a suscribir con Edison Lanza, relator especial para la Libertad de Expresión de la OEA, que la sociedad actual está ante una "tormenta perfecta" que en el remolino de mentiras y manipulaciones pone en riesgo no solo los valores de confianza y credibilidad, sino también el propio edificio de la democracia.

Si bien la historia nos muestra que el engaño y la mentira han sido armas usadas desde siempre para la conquista del poder, los avances tecnológicos, a caballo de algoritmos, inteligencia artificial y big data, nos revelan en pleno siglo 21 que la manipulación de información y datos adquiere tamaño y efectos impresionantes, como los que se han 
generado con el ya conocido uso de metadatos por parte de Cambridge Analitycs en relación a las elecciones en los EEUU.

Organismos de monitoreo sobre la libertad de expresión tienen acentuada preocupación sobre este asunto. En el marco de las celebraciones del presente año 2020 con motivo del Día Mundial de la Libertad de Prensa (3 de mayo), el Relator Especial de las Naciones Unidas (ONU) para la Libertad de Opinión y de Expresión, el representante para la Libertad de los Medios de Comunicación de la Organización para la Seguridad y la Cooperación en Europa (OSCE) y el Relator Especial para la Libertad de Expresión de la Organización de los Estados Americanos (OEA) suscribieron una Declaración Conjunta sobre Libertad de Expresión y Elecciones en la Era Digital (OAS, 2020) en la que denunciaron que "la desinformación deliberada, la información errónea o manipulada, diseminada con intención de dañar, así como las 'expresiones de odio', pueden generar y exacerbar tensiones vinculadas con las elecciones". Se manifestaron "alarmados" por el "uso indebido de las redes sociales, por parte de actores estatales y privados, para subvertir los procesos electorales, incluso a través de diversas formas de comportamiento no auténtico y el uso de 'propaganda computacional' (emplear herramientas automatizadas para influir sobre el comportamiento)"

Dicha declaración exhorta a los Estados, entre otras cosas, a "evaluar la posibilidad de respaldar medidas positivas para abordar el problema de la desinformación en línea, como la promoción de instancias independientes para la verificación de información y campañas de educación pública, y al mismo tiempo, evitar adoptar normas para criminalizar la diseminación de desinformación". Sin duda, aunque la preocupación por la desinformación es señalada, también hay un criterio de precaución para no caer en la “criminalización" que pudiera poner en riesgo -por derivación- la propia libertad de expresión.

Los declarantes insisten en que el camino de la regulación legal debe evitar la censura. Señalan que "Ios Estados deben cerciorarse de que todas las restricciones sobre la libertad de expresión que se apliquen durante períodos electorales cumplan con los requisitos del test tripartito del derecho internacional sobre legalidad, legitimidad del 
fin perseguido y necesidad, lo cual implica lo siguiente:1) No debe haber censura previa de los medios de comunicación, lo que incluye el bloqueo administrativo de sitios web de medios y las interrupciones del servicio de Internet. 2) Toda limitación que afecte el derecho a difundir pronunciamientos electorales debe cumplir con los estándares internacionales aplicables, que incluyen la necesidad de que las figuras públicas toleren un mayor nivel de críticas y escrutinio que los ciudadanos comunes. 3) No deben establecerse leyes generales ni ambiguas sobre desinformación, como prohibiciones respecto a la difusión de 'falsedades' o 'información no objetiva" (OAS, 2020).

Particular mención hacen en dicha Declaración sobre los "actores digitales", especialmente los intermediarios de internet, los medios y plataformas digitales. Expresan que deben esforzarse y tomar debidas diligencias para que sus "productos y servicios" no afecten los derechos humanos, así como, aseguren medidas para posibilitar el acceso de los usuarios a la diversidad de ideas y perspectivas políticas. "En particular, deberían cerciorarse de que las herramientas automáticas, como los algoritmos de clasificación, no obstaculicen indebidamente - sea o no de manera intencional - el acceso a contenidos relacionados con elecciones y la disponibilidad de diversos puntos de vista para los usuarios", dice expresamente el documento.

En el mismo sentido, los expertos citados manifiestan que "los medios digitales y los intermediarios de internet deberían realizar esfuerzos suficientes para abordar la desinformación, la información errónea o manipulada intencionalmente", lo cual incluye "la promoción de instancias de verificación independientes y la implementación de otras medidas, como mantener archivos respecto a la publicidad política contratada, moderación apropiada de contenidos y alertas públicas" (OAS, 2020).

Las preocupaciones, advertencias y exhortaciones emitidas en el citado manifiesto no están en absoluto dislocadas de la realidad. Las fake news se han constituido en un problema grave que afecta al derecho a la información, y en particular, al que debería regir en los procesos electorales. La construcción de la democracia requiere de un debate de ideas y opiniones que se sustenta sobre las bases del libre flujo de información y no puede encontrar caminos eficientes si el ecosistema comunicacional 
está infestado de desinformación, falsedades y manipulación. El poder de la información es real para promover una opinión pública vigorosa, concientizada, crítica, capaz de ejercer un rol eficaz en el juego de la democracia. Pero el poder de la desinformación puede destruir, tergiversar y manipular todo eso.

En el curso que UNESCO y la Red Iberoamericana de Escuelas Judiciales imparten periódicamente desde hace unos años para capacitar a magistrados judiciales sobre libertad de expresión se abordan muchos temas vinculados a este derecho, y en particular, a la libertad de expresión en internet. Al respecto, se sostiene que "el principio de neutralidad de la red establece que la información que circula por Internet no debe ser objeto de ningún tipo de interferencia, manipulación o bloqueo en función de su contenido, sea por el Estado o por actores privados". Citando a la Declaración Conjunta de los Relatores sobre Libertad de Expresión e Internet del año 2011, dicho principio sostiene que el tratamiento de los datos y el tráfico de Internet no debe ser objeto de ningún tipo de discriminación en función de factores como dispositivos, contenido, autor, origen y/o destino del material, servicio o aplicación". Esto implica principalmente que "la libertad de acceso y elección de los usuarios de utilizar, enviar, recibir u ofrecer cualquier contenido, aplicación o servicio legal por medio de Internet no esté condicionada, direccionada o restringida, por medio de bloqueo, filtración o interferencia" (RIAEJ, UNESCO, 2017)

Los riesgos son reales. $Y$ se hacen más preocupantes cuando asistimos a una realidad cada vez más extendida, donde las polarizaciones ideológicas o la escasa importancia dada a la formación crítica de ciudadanos para la era tecnológica, hacen presumir perspectivas pesimistas en cuanto a estas libertades ejercidas en el mar de la desinformación. Por algo, organismos internacionales como UNESCO postulan y alientan a una "alfabetización digital" o una "educación mediática" necesarias para la formación de ciudadanos para este tiempo. Al decir de Guilherme Canela, consejero para Información y Comunicación de UNESCO, es sustancial incorporar esta formación incluso en la educación formal a fin de desarrollar un pensamiento crítico en torno a la diversidad de contenidos a los cuales las personas (niños, jóvenes, adultos) están expuestas ante los medios y las plataformas de comunicación, todo lo cual “les permitirá 
identificar contenidos de riesgo, como las llamadas fake news" (Canela, 2019) En ese sentido, "no hay un país en el planeta donde se pueda identificar una política pública nacional sostenible en la línea del tiempo, que haya incluido este tema de manera definitiva en las políticas educativas", señaló Canela en el marco del Panel titulado “Antídotos contra la desinformación", celebrado en Lima, Perú, en marzo de 2019, bajo organización de UNESCO y la entidad de fact checking "Ojo Público".

Las noticias falsas son una amenaza real y presente para la democracia. Y cuando uno piensa que en el ámbito del periodismo y la prensa deben darse la principales manifestaciones de solvencia, criticidad y eficiencia para enfrentar el desafío de las fake news con herramientas oportunas y eficaces, no pueden dejar de ser preocupantes las ideas que en dicho sector pudieran estar ganando terreno en cuanto a preferir métodos de criminalización, cancelación y censura como estrategias para combatir la desinformación. Los avances del estudio realizado con comunicadores de Paraguay, y su correlato puntual con profesionales de la región latinoamericana, nos ponen ante una luz amarilla en el camino: desde el propio periodismo profesional se podrían estar incubando preferencias y apoyos para el retorno a prácticas totalitarias de censura, bajo pretexto de la necesidad de "regular" el flujo de la información debido a la avalancha de noticias falsas en las redes sociales de internet.

Los riesgos son reales. Pero las perspectivas parecen peores si, tomando en cuenta ese estudio, se considera en contrapartida que justamente la prensa y el periodismo deben ser articuladores de un combate a las fake news basado en la más férrea defensa de la libertad de expresión. Por lo que indica quizás muy preliminarmente el sondeo, parece haber un "monstruo" de censura que se está alimentando en el ámbito del periodismo en estos tiempos de fake news y pandemia. La "desinfodemia" de la que nos hablan UNESCO y los expertos trae consigo una carga viral impensable para inocular de afanes totalitarios una de las células más relevantes del tejido de la democracia: la prensa. La grieta de vulnerabilidad aprovechada es el impacto de la desinformación y una creciente revitalización de ideas ligadas a la represión y la censura. Bajo el propósito ético de defender la información veraz, se podría estar enterrando lenta pero sostenidamente el propio derecho a la información y el libre flujo de ideas u pensamientos en la sociedad. 
Los riesgos son reales. Pero, no obstante, las herramientas para revertir este moldeado perverso, las armas para combatir el apabullante avance de las fake news -viniere de donde viniere tal empuje- no pueden ser las que pongan a su vez en mayor riesgo y compromiso los valores y estándares de la libertad de expresión. La lucha será inútil -y hasta pueden ser peores los resultados- si para enfrentar la "tormenta perfecta" de las fake news terminamos generando oleadas de censura y restricciones ilegítimas que completen finalmente el ahogo total e irreparable de la libertad de expresión.

A las fake news no se las combate con censura. Se las debe neutralizar con mayor y mejor información. Y para ello, el periodismo, los periodistas, pueden aportar mucho y de manera relevante fortaleciendo el empeño en aras de un periodismo de calidad, realmente comprometido con la sociedad y la democracia.

\section{REFERENCIAS BIBLIOGRÁFICAS}

Canela, G. (28 de marzo de 2019). Ministerio de Comunicaciones Perú. Recuperado el 14 de junio de 2020, de http://www.concortv.gob.pe/noticias/unesco-educacionmediatica-debe-incluirse-en-la-escuela-para-prevenir-influencia-de-las-noticias-falsasen-la-ninez-y-adolescencia/

Ético, R. d., EJN Red de Periodismo ético, y EJN. (Noviembre de 2017). Ethical Journalism Network. Obtenido de https://ethicaljournalismnetwork.org/fake-newsbusiness-democracy

IFJ. (2019). IFJ - International Federation of Journalists. Recuperado el 20 de MAYO de 2020, de https://www.ifj.org/fileadmin/user_upload/Fake_News__FIP_AmLat.pdf

Mackenna, M. (MAYO de 2020). Knight Center for Journalism. Disponible en https://www.kccourses.org

OAS. (3 de mayo de 2020). OAS ORG. Recuperado el 15 de junio de 2020, de Organización de Estados Americanos - Comisión Interamericana de Derechos Humanos: http://www.oas.org/es/cidh/expresion/showarticle.asp?artID=1174\&IID=2

Peirano, M. (2019). El enemigo conoce el sistema. Barcelona: Penguin Ramdom House. 
Restrepo, J. D. (2019). Consultorio Ético - Fundación Gabo. Recuperado el 20 de mayo de 2020, de https://fundaciongabo.org/es/consultorio-etico/consulta/2094

RIAEJ, UNESCO (2017). Caja de herramientas para Escuelas Judiciales Iberoamericanas sobre Libertad de Expresión. Montevideo: UNESCO.

UNESCO. (Julio de 2017). Correo de la UNESCO. Obtenido de https://es.unesco.org/courier/july-september-2017/informacion-falsa-opinionperiodistas

UNESCO. (2020). Periodismo, "noticias falsas" \& desinformación: manual de educación y capacitación en periodismo. Santo Domingo: UNESCO.

Waisbord, S. (30 de MAYO de 2020). ¿Cómo generar información confiable durante la pandemia? (WINN, Editor) Recuperado el 20 de JUNIO de 2020, de https://winnlatam.com/silvio-waisbord-como-generar-informacion-confiable-en-uncontexto-de-pandemia-2/ 